\title{
Combining FoxP3 and Helios with GARP/LAP markers can identify expanded Treg subsets in cancer patients
}

\author{
May Abd Al Samid ${ }^{1,2, *}$, Belal Chaudhary, ${ }^{1,}$, Yazan S. Khaled ${ }^{3}$, Basil J. Ammori ${ }^{3}$, \\ Eyad Elkord ${ }^{1,2,3}$ \\ ${ }^{1}$ Biomedical Research Centre, School of Environment and Life Sciences, University of Salford, Manchester, United Kingdom \\ ${ }^{2}$ College of Medicine and Health Sciences, United Arab Emirates University, Al Ain, United Arab Emirates \\ ${ }^{3}$ Institute of Cancer Sciences, University of Manchester, Manchester, United Kingdom \\ *These authors contributed equally to this work
}

Correspondence to: Eyad Elkord, e-mail: eelkord@uaeu.ac.ae, e.elkord@salford.ac.uk and eyad.elkord@manchester.ac.uk

Keywords: regulatory $T$ cells, markers, GARP/LAP, FOXP3, Helios

Received: December 09, 2015

Accepted: January 29, 2016

Published: February 11, 2016

\section{ABSTRACT}

Regulatory $\mathbf{T}$ cells (Tregs) comprise numerous heterogeneous subsets with distinct phenotypic and functional features. Identifying Treg markers is critical to investigate the role and clinical impact of various Treg subsets in pathological settings, and also for developing more effective immunotherapies. We have recently shown that non-activated FoxP3-Helios ${ }^{+}$and activated FoxP3 ${ }^{+/-}$Helios $^{+} \mathrm{CD4}^{+}{ }^{+}$cells express GARP/LAP immunosuppressive markers in healthy donors. In this study we report similar observations in the peripheral blood of patients with pancreatic cancer (PC) and liver metastases from colorectal cancer (LICRC). Comparing levels of different Treg subpopulations in cancer patients and controls, we report that in PC patients, and unlike LICRC patients, there was no increase in Treg levels as defined by FoxP3 and Helios. However, defining Tregs based on GARP/LAP expression showed that FoxP3LAP ${ }^{+}$Tregs in non-activated and activated settings, and FoxP3 $3^{+}$Helios $^{+}$GARP ${ }^{+}$LAP ${ }^{+}$ activated Tregs were significantly increased in both groups of patients, compared with controls. This work implies that a combination of Treg-specific markers could be used to more accurately determine expanded Treg subsets and to understand their contribution in cancer settings. Additionally, GARP $-/+\mathrm{LAP}^{+} \mathrm{CD4}^{+} \mathrm{T}$ cells made IL-10, and not IFN-Y, and levels of IL-10-secreting CD4 ${ }^{+} T$ cells were elevated in LICRC patients, especially with higher tumor staging. Taken together, our results indicate that investigations of Treg levels in different cancers should consider diverse Treg-related markers such as GARP, LAP, Helios, and others and not only FoxP3 as a sole Treg-specific marker.

\section{INTRODUCTION}

Regulatory T cells (Tregs) are immunosuppressive cells with key roles in immune tolerance and immune dysregulation in pathological settings including inflammation, autoimmunity and cancer [1]. In cancers, Tregs accumulate in peripheral tissues and tumors where, in conjunction with other immunosuppressive cells, they inhibit tumor specific immune responses and contribute to the development of a tolerogenic tumor microenvironment enabling immune evasion [2,3]. Elevated Treg levels have been reported to correlate with tumor progression, impaired $\mathrm{T}$ cell functionality and negative prognosis in different cancers [4-7]. Given their role in immune evasion and poor clinical outcomes, Tregs have become an important target for novel cancer immunotherapies $[3,8-10]$.

In recent years, it has become increasingly clear that Tregs comprise diverse subsets with distinct phenotypic and functional features [11-15]. Understanding the role and contribution of specific Treg subsets is critical to harnessing the potential of different therapeutic modalities. Tregs are generally divided into thymic-derived Tregs (tTregs) and peripheral-induced Tregs (pTregs), traditionally defined by expression of the forkhead box P3 transcription factor (FoxP3) and IL-2 receptor alpha chain (CD25). In addition, two FoxP3- pTreg subsets have been identified; Tr1 and Th3 cells. Significant 
efforts have been made into identifying effective markers for Treg subset identification, isolation and therapeutic manipulation $[4,15,16]$. Both CD25 and FoxP3 can be up-regulated on non-suppressive Teff and activated $\mathrm{T}$ cells, while FoxP3 as an intracellular marker does not allow Treg isolation [17]. Promising Treg markers include the late-stage Treg activation markers, glycoprotein A repetitions predominant (GARP) and latency-associated peptide (LAP), and the Ikaros zinc finger transcription factor Helios.

Helios has been suggested to play important roles in immune regulation by repressing pro-apoptotic genes in Tregs, contributing to the development of follicular Tregs, and enhancing Treg function in cooperation with FoxP3 $[18,19]$. Despite its seemingly ubiquitous expression, it is accepted that Helios can define highly suppressive Treg subsets in various settings. FoxP $3^{+/}$Helios $^{+}$Tregs are significantly expanded in the peripheral blood and at tumor sites of various cancers, and have been reported to exhibit enhanced in vitro suppressive activity [20,21].

GARP and LAP are well-characterized late-stage Treg activation markers, and they contribute directly to a contact-dependent TGF- $\beta$-mediated suppressive mechanism in Tregs $[22,23]$. LAP is a propeptide that binds non-covalently with transforming growth factor beta (TGF- $\beta$ ) forming an inactive latent LAP-TGF- $\beta$ complex, and TGF- $\beta$ is cleaved from the latent complex releasing active TGF- $\beta$ [22]. LAP has been utilized to isolate highly suppressive Tregs in in vitro expansion cultures and also from the peripheral blood of cancer patients following CTLA-4 immunotherapy [24, 25]. GARP is a transmembrane protein that plays a critical role in the formation and expression of LAP-TGF- $\beta$ complexes by anchoring the complexes to the cell membrane [23].

We have recently shown that non-activated FoxP3 Helios $^{+}$and activated FoxP3 ${ }^{+/}$Helios $^{+} \mathrm{CD}^{+} \mathrm{T}$ cells isolated from the peripheral blood of healthy donors co-express GARP and LAP [26]. In the current study we report similar observations in $\mathrm{T}$ cells isolated from the peripheral blood of patients with pancreatic cancer (PC) and patients with liver metastases from colorectal cancer (LICRC). In addition, we show that FoxP3 $3^{+/-}$ Helios $^{+} \mathrm{GARP}^{+} \mathrm{LAP}^{+}$activated Treg subsets are expanded in PC and LICRC patients, compared with healthy donors. We also report that $\mathrm{CD}^{+} \mathrm{GARP}^{+/-} \mathrm{LAP}^{+} \mathrm{T}$ cells make IL-10 but not IFN- $\gamma$, and they are increased in LICRC patients.

\section{RESULTS}

\section{LAP is expressed significantly higher than GARP on activated $\mathrm{CD}^{+} \mathrm{T}$ cells in healthy donors and pancreatic cancer patients}

Peripheral blood samples were collected from PC and LICRC patients and chronic pancreatitis (CP) and Healthy donor (HD) controls. as detailed in Table 1.
We first compared the expression of LAP and GARP, as markers of activated Tregs, on $\mathrm{CD}^{+} \mathrm{T}$ cells isolated from the peripheral blood of $\mathrm{HD}$ and $\mathrm{PC}$ patients. LAP and GARP were expressed at low levels on $\mathrm{CD}^{+}{ }^{+} \mathrm{T}$ cells in the steady state $(<1 \%$ for $\mathrm{HD}$ and $<2 \%$ for PC patients, data not shown). Following in vitro activation with anti-CD3/28, both GARP and LAP were significantly up regulated on $\mathrm{CD}^{+} \mathrm{T}$ cells, as expected. However, expression of LAP was higher than GARP on $\mathrm{CD}^{+} \mathrm{T}$ cells. This difference was significant in healthy donors (LAP: $3.15 \pm 0.35 \%$ vs. GARP $2.46 \pm 0.39 \%$; Figure $1 \mathrm{~A}$ and $1 \mathrm{~B}$ ) and PC patients (LAP: $5.41 \pm 0.51 \%$ vs. GARP: $4.73 \pm 0.52 \%$; Figure $1 \mathrm{C}$ and $1 \mathrm{D})$.

\section{Levels of $\mathrm{FoxP3}^{+} \mathrm{LAP}^{-}$, $\mathrm{FoxP3}^{+} \mathrm{LAP}^{+}$and FoxP3 $^{-} \mathrm{LAP}^{+}$Treg subsets in cancer patients and controls}

We then analyzed FoxP3 and LAP co-expression on non-activated $\mathrm{CD}^{+} \mathrm{T}$ cells (Figure 2 ). We found that LAP was co-expressed with FoxP3 at very low levels $(<0.2 \%)$ on non-activated $\mathrm{CD} 4^{+}$Tregs from HD, CP, PC and LICRC. This is consistent with our recent finding in healthy donors [26].

Most studies determine Treg levels based on FoxP3 expression. Defining Tregs based on FoxP3 expression alone, there was no significant increase in the $\mathrm{FoxP}^{+} \mathrm{LAP}$ Treg subset in PBMCs from PC $(3.46 \pm 0.28 \%)$, compared to $\mathrm{HD}(3.04 \pm 0.36 \%)$ and $\mathrm{CP}(3.46 \pm 0.41 \%)$ (Figure $2 \mathrm{~B})$. However, the FoxP3 ${ }^{+} \mathrm{LAP}^{-}$Treg subset was significantly increased in PBMCs from LICRC patients $(6.90 \pm 1.11 \%)$, compared with PC patients and HD (Figure 2B). A very small population $(<0.2 \%)$ of double-positive FoxP $3^{+} \mathrm{LAP}^{+}$ $\mathrm{T}$ cells was detected in all samples, but it was higher in LICRC patients compared with HD (Figure 2C). Interestingly, defining Tregs as $\mathrm{FoxP}^{-} \mathrm{LAP}^{+}$, there were significant increases both in LICRC $(1.98 \pm 0.37 \%)$ and PC $(1.39 \pm 0.21 \%)$ samples, compared with HD $(0.70 \pm$ $0.11 \%)$ and $\mathrm{CP}$ controls $(0.60 \pm 0.25 \%)$ (Figure $2 \mathrm{D})$.

We further analyzed the levels of $\mathrm{LAP}^{+-}$and $\mathrm{FoxP}^{++-} \mathrm{CD}^{+} \mathrm{T}$ cell subsets following in vitro activation with anti-CD3/28 (Figure 3). We observed similar results to those in the non-activated setting. The FoxP $3^{+} \mathrm{LAP}^{-}$ Treg subset was significantly expanded only in LICRC $(6.25 \pm 0.85 \%)$ compared with HD $(3.82 \pm 0.42 \%)$ (Figure 3B), and they were higher than PC (4.60 $\pm 0.40 \%)$ although this did not reach significance. The doublepositive $\mathrm{FoxP}^{+}{ }^{+} \mathrm{LAP}^{+}$Treg subset was higher in activated samples (Range in all groups: 1.06-1.64), compared with non-activated samples (Figure 2C and 3C). As expected, the FoxP3- ${ }^{-} \mathrm{LP}^{+}$Treg subset was increased in activated cells (Range in all groups: 1.77-3.63), compared with non-activated cells (Range in all groups: 0.6-1.98). Similar to non-activated cells, the FoxP3- ${ }^{-} \mathrm{AP}^{+}$subset was expanded in activated cells both in LICRC $(3.63 \pm 0.50 \%)$ and PC (3.27 $\pm 0.37 \%)$, compared with HD $(1.79 \pm 0.27 \%)$ and $\mathrm{CP}$ controls $(1.77 \pm 0.30 \%)$ (Figure $3 \mathrm{D})$. 
Table 1: Characteristic features of study subpopulations

\begin{tabular}{|c|c|c|c|c|}
\hline & PC & $\mathbf{C P}$ & & CRC \\
\hline Number & $n=20$ & $n=9$ & & $n=11$ \\
\hline Age (median) & $62(47-87)^{*}$ & $54(31-84)^{*}$ & & $73(71-83)^{*}$ \\
\hline Gender (Male: Female) & $13: 7$ & $5: 4$ & & $8: 3$ \\
\hline \multicolumn{5}{|l|}{ TNM stage } \\
\hline $\mathbf{I}$ & 0 & - & & 1 \\
\hline II & 4 & - & & 5 \\
\hline III & 1 & - & & 5 \\
\hline IV & 15 & - & & - \\
\hline Tumor size (cm) & $2.9(1.9-5.5)^{*}$ & & & $4.2(1-13)^{*}$ \\
\hline Preoperative CA19-9 (0-37 U/ml) & $371(77-1230)^{*}$ & 49 & & $63.9(1-169)^{*}$ \\
\hline Preoperative CEA $(<2.5 \mathrm{ng} / \mathrm{ml})$ & $5(5-13) *$ & - & & $29.5(1-144)^{*}$ \\
\hline \multicolumn{5}{|l|}{ Tumor site } \\
\hline Head of pancreas & 18 & - & Right-sided origin & 7 \\
\hline Body of pancreas & 0 & - & Left-sided origin & 3 \\
\hline Tail of pancreas & 2 & - & Others & 1 \\
\hline \multicolumn{5}{|l|}{ Histological grade } \\
\hline Well/moderate & 9 & - & & 11 \\
\hline Poor/undifferentiated & 11 & - & & 0 \\
\hline
\end{tabular}

Abbreviations: PC: pancreatic cancer; CP: chronic pancreatitis; CRC: colorectal; CA19-9: cancer antigen 19-9; CEA: carcinoembryonic antigen. *Data shown represent median (range).

These results emphasize the importance of determining Treg levels by considering different Tregrelated markers and not only based on FoxP3 expression as the sole Treg-specific marker.

\section{FoxP3 $^{+-}$Helios $^{+} \mathbf{T}$ cells are expanded in LICRC patients in non-activated and activated settings}

Next, we combined FoxP3 and Helios staining and compared FoxP3 ${ }^{+/}$Helios $^{+/}$T cell subpopulations in cells isolated from HD, CP, PC and LICRC in non-activated and activated settings (Figure 4 ). We previously reported that the expanded FoxP3 ${ }^{+}$Treg subset from peripheral blood of untreated renal cell carcinoma patients and also following IL-2 treatment co-express Helios [27]. In this study, we found that FoxP ${ }^{+} \mathrm{Helios}^{+}$and FoxP3 ${ }^{-} \mathrm{Helios}^{+} \mathrm{T}$ cell subsets were significantly higher than FoxP $3{ }^{+}$Helios Tregs in all subgroups (Figure 4). There was no significant difference in levels of FoxP ${ }^{+}{ }^{+}$Helios $^{-} \mathrm{T}$ cells between patients and controls both in activated and non-activated settings (Figure 4B and 4C). However, FoxP3 ${ }^{+} \mathrm{Helios}^{+}$ and FoxP3 ${ }^{-}{ }^{-H e l i o s}{ }^{+} \mathrm{T}$ cell subsets were expanded only in peripheral blood of LICRC samples both in non-activated (Figure 4B) and activated cells (Figure 4C), compared with $\mathrm{PC}$ and $\mathrm{HD}$ (Figure $4 \mathrm{~B}$ and $4 \mathrm{C}$ ). There were no significant differences between $\mathrm{HD}, \mathrm{CP}$ and $\mathrm{PC}$ samples in the FoxP3 ${ }^{+/}$Helios $^{+} \mathrm{T}$ cell subpopulations. Of interest, the FoxP ${ }^{+} \mathrm{Helios}^{+}$and FoxP3 ${ }^{-} \mathrm{Helios}^{+} \mathrm{T}$ cell subsets in LICRC patients were not significantly expanded following activation (Figure 4B and 4C). On the other hand, the FoxP $3^{+}$Helios $^{-}$subset was expanded following activation (Range in all groups: non-activated: $0.49-0.73 \%$ and activated: $1.77-2.45)$.

\section{GARP/LAP expression on FoxP3 ${ }^{+/-}$Helios $^{+/-} \mathbf{T}$ cell subsets in cancer patients, compared with healthy donors}

We further investigated co-expression of LAP and GARP on FoxP3 ${ }^{+-}$Helios $^{+/}$T cell subsets in HD, PC and LICRC patients in non-activated (Figure 5) and activated settings (Figure 6). We have recently reported that the only subpopulation that expressed significantly higher levels of GARP/LAP, compared with other subpopulations, was $\mathrm{CD}^{+}{ }^{+} \mathrm{FoxP}^{-} \mathrm{Helios}^{+}$in healthy donors in the nonactivated setting (Figure 5B and [26]). Herein, we report similar observations in cells isolated from PC (Figure 5C) and LICRC patients (Figure 5D). Interestingly, levels of 
A

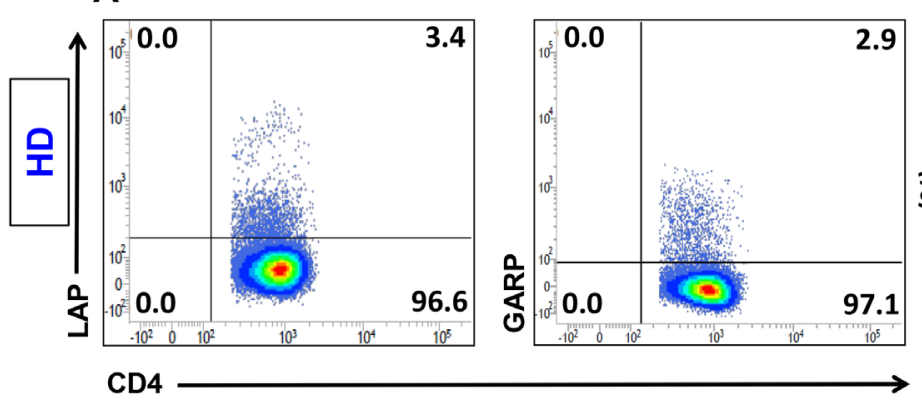

C

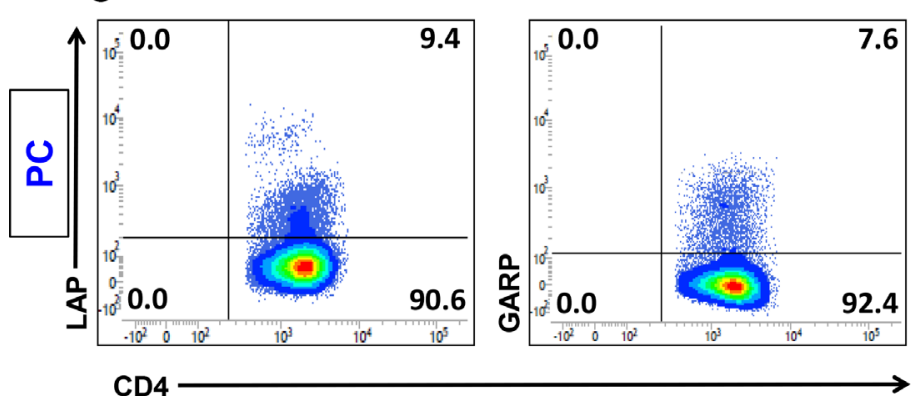

B

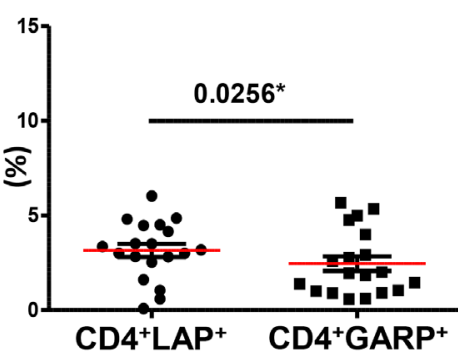

D

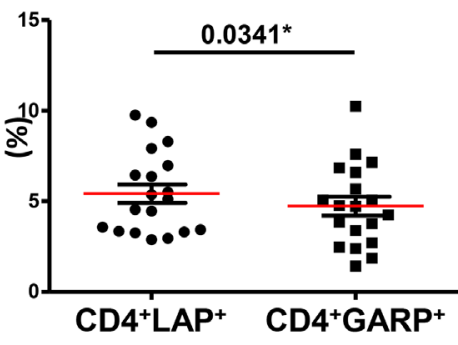

Figure 1: Expression of LAP or GARP on activated CD4 ${ }^{+} \mathbf{T}$ cells. PBMCs from 19 healthy donors (HD) and 19 pancreatic cancer (PC) patients were activated by plate-bound anti-CD3/28 followed by staining for LAP and GARP. Representative flow cytometric plots showing LAP (first plots) or GARP (second plots) expression on $\mathrm{CD}^{+} \mathrm{CD}^{+} \mathrm{T}$ cells isolated from $\mathrm{HD}(\mathbf{A})$ and PC patients (C). Scatter plots show the mean percentages $\pm \mathrm{SEM}$ of $\mathrm{CD} 4^{+} \mathrm{LAP}^{+} \mathrm{T}$ cells compared with $\mathrm{CD} 4^{+} \mathrm{GARP}^{+} \mathrm{T}$ cells in activated PBMCs isolated from HD (B) and PC patients (D).

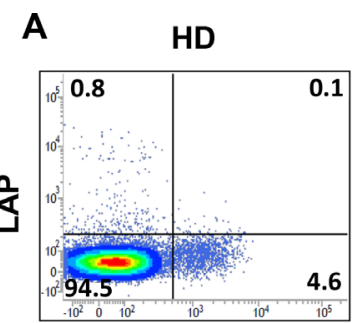

FoxP3
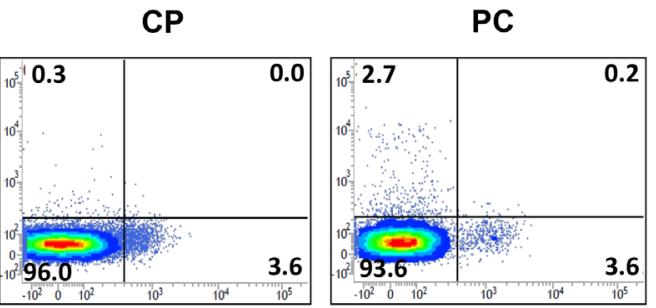

LICRC

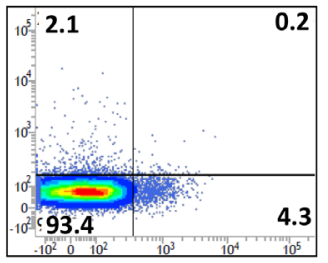

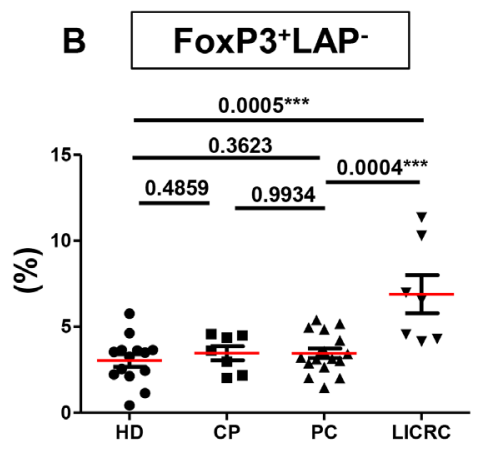
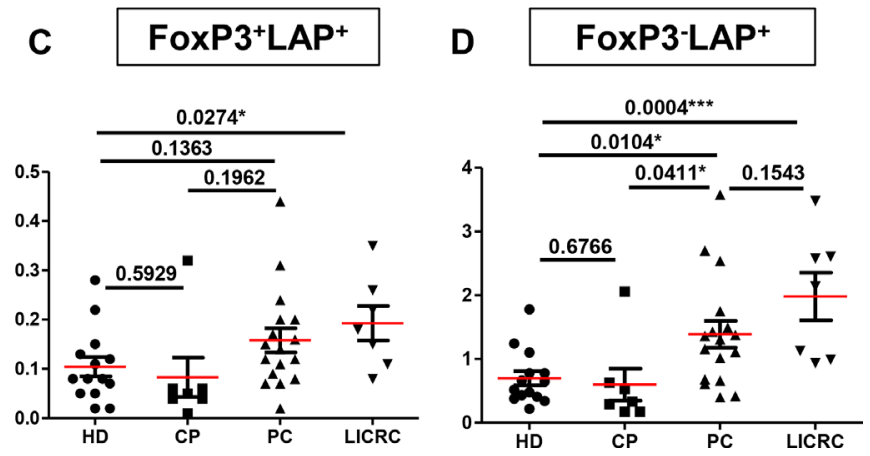

Figure 2: Comparisons between healthy donors and patients for the expression of LAP on non-activated FoxP3 ${ }^{+/}$T cell subsets. Thawed PBMCs isolated from 14 healthy donors (HD), 7 chronic pancreatitis (CP), 17 pancreatic cancer (PC), and 7 liver metastases from colorectal cancer (LICRC) patients were stained for surface and intracellular markers. (A) Representative flow cytometric plots showing FoxP3 expression against LAP, gated on $\mathrm{CD}^{+} \mathrm{CD}^{+}{ }^{+} \mathrm{T}$ cells from healthy donors and patients. Scatter plots show the mean percentages \pm SEM of FoxP3 ${ }^{+} \mathrm{LAP}^{-}(\mathbf{B}), \mathrm{FoxP}^{+} \mathrm{LAP}^{+}(\mathbf{C})$ and FoxP3 ${ }^{-} \mathrm{LAP}^{+} \mathrm{T}$ cells $(\mathbf{D})$. 
$\mathrm{CD}^{+}{ }^{+}$FoxP $3-{ }^{-}$Helios $^{+} \mathrm{GARP}^{+} \mathrm{LAP}^{+}$Tregs were significantly expanded in LICRC samples (10.41 $\pm 3.09 \%$, Figure 5E), compared with healthy donors $(4.66 \pm 0.86 \%)$. There was an increase in this Treg subset in PC $(9.60 \pm 2.36 \%$, Figure 5E) compared with HD, although this did not reach statistical significance $(P=0.0801)$.

Following TCR stimulation, GARP/LAP were up regulated on all $\mathrm{T}$ cell subsets $\left(\mathrm{FoxP}^{+} \mathrm{Helios}^{+}\right.$, FoxP3 Helios $^{+}$and FoxP3 ${ }^{+}$Helios $^{-}$) except the FoxP3 ${ }^{-}$Helios $^{-} \mathrm{T}$ cell subset (Figure 6B-6D). As we found in HD (Figure 6B and [26]), GARP/LAP were mainly expressed on the FoxP $^{+}{ }^{+}$Helios $^{+} \mathrm{T}$ cell subset in activated cells from PC (Figure 6C) and LICRC patients (Figure 6D). Interestingly, the $\mathrm{CD}^{+}{ }^{+} \mathrm{FoxP}^{+}{ }^{+}$Helios ${ }^{+} \mathrm{GARP}^{+} \mathrm{LAP}^{+}$Treg subset was significantly expanded in PC and LICRC samples, compared with healthy donors (Figure 6E). Similar to the non-activated setting, the $\mathrm{CD} 4^{+} \mathrm{FoxP}^{-}{ }^{-} \mathrm{Helios}^{+} \mathrm{GARP}^{+} \mathrm{LAP}^{+}$ subset was significantly expanded only in LICRC samples, compared with HD (Figure 6F), and their levels were higher in $\mathrm{PC}$ than HD, although this did not reach significance $(P=0.0747)$. GARP/LAP expression on FoxP $3^{+}$Helios $^{-}$Tregs were significantly lower than their expression on FoxP3 ${ }^{+} \mathrm{Helios}^{+}$and FoxP3 $-\mathrm{Helios}^{+}$ in healthy donors and cancer patients (Figure 6B-6D). There were no significant differences in GARP/LAP expression on FoxP $3^{+} \mathrm{Helios}^{-}$Tregs between HD $(6.51 \pm 0.92 \%), \mathrm{PC}(8.36 \pm 1.04 \%)$ and LICRC patients $(8.60 \pm 1.18 \%)$. The potential role of the FoxP $3{ }^{+}$Helios Treg subset in these cancers could be less significant as they were not expanded in cancer patients, at least in peripheral blood.

\section{GARP $^{-/+} \mathrm{LAP}^{+} \mathrm{CD4}^{+} \mathrm{T}$ cells make IL-10 and their levels are higher in LICRC patients}

In order to further define the lineage of LAP and GARP expressing CD4 ${ }^{+}$T cells, we investigated the IL-10 and IFN- $\gamma$ secretion profile of $\mathrm{GARP}^{+/} \mathrm{LAP}^{+/-}$subsets (Figure 7). PBMCs from healthy donors and LICRC patients were activated with anti-CD3/28 in order to induce GARP/LAP expression and stimulate cytokine secretion, followed by addition of Golgi Plug for 4 hours to retain cytokines inside cells. In healthy donors and LICRC patients, the GARP ${ }^{+} \mathrm{LAP}^{+} \mathrm{T}$ cell subset contained

A
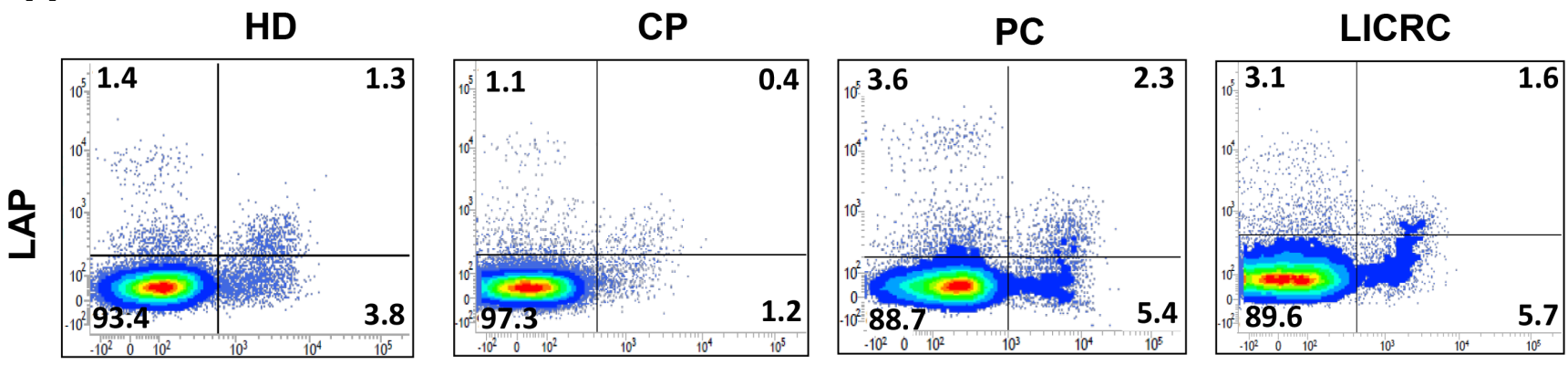

FoxP3
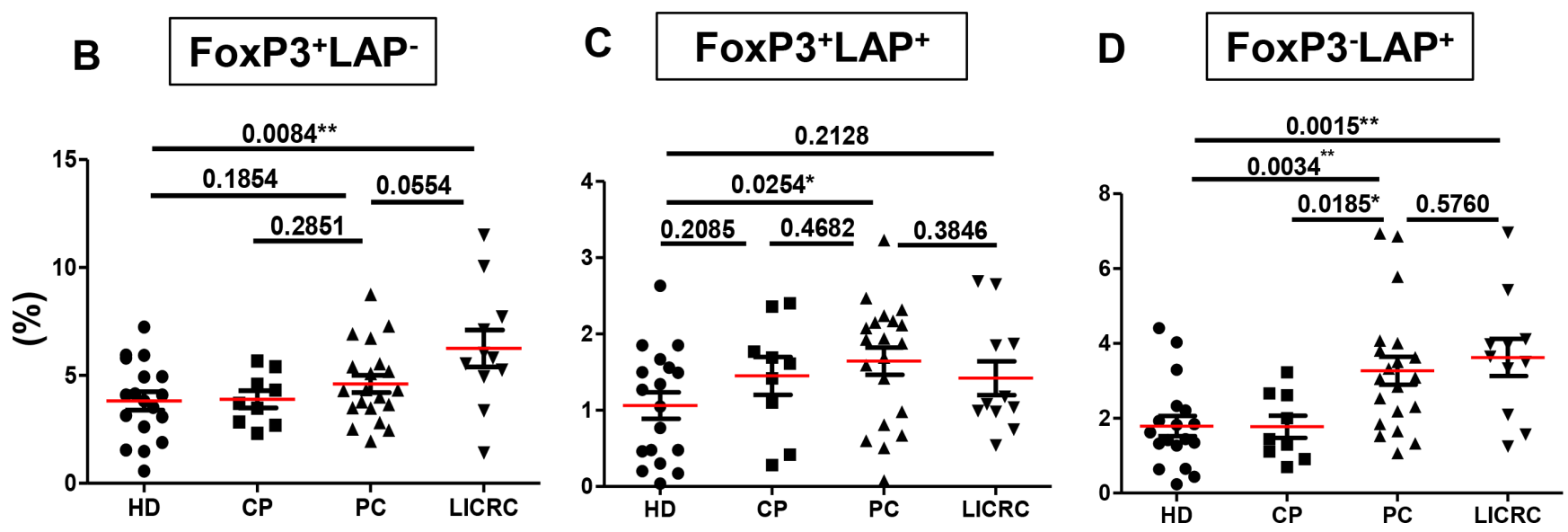

Figure 3: Comparisons between healthy donors and patients for the expression of LAP on activated FoxP3 ${ }^{+/-}$T cell subsets. Thawed PBMCs isolated from 18 healthy donors (HD), 9 chronic pancreatitis (CP), 20 pancreatic cancer (PC), and 11 liver metastases from colorectal cancer (LICRC) patients were activated by plate-bound anti-CD3/28 and then stained for surface and intracellular markers. (A) Representative flow cytometric plots showing FoxP3 expression against LAP, as gated on $\mathrm{CD}^{+} \mathrm{CD}^{+} \mathrm{T}$ cells from both healthy donors and patients. Scatter plots show the mean percentages \pm SEM of FoxP3 ${ }^{+} \mathrm{LAP}^{-}(\mathbf{B}), \mathrm{FoxP}^{+} \mathrm{LAP}^{+}(\mathbf{C})$ and FoxP3 ${ }^{-} \mathrm{LAP}^{+} \mathrm{T}^{-}$cells $(\mathbf{D})$. 
the most IL-10 secreting and IFN- $\gamma$ non-secreting $\mathrm{CD}^{+}$ T cells, defined as IL- $10^{+}$IFN- $\gamma^{-}$. The GARP ${ }^{-} \mathrm{LAP}^{+} \mathrm{CD}^{+}$ $\mathrm{T}$ cell subset contained a lower level of IL-10+ IFN- $\gamma^{-} \mathrm{T}$ cells (Figure 7A and 7B). In healthy donors and LICRC samples, the $\mathrm{GARP}^{+} \mathrm{LAP}^{+} \mathrm{T}$ cell subsets made significantly higher levels of IL-10 compared to the GARP- $\mathrm{LAP}^{+} \mathrm{T}$ cell subsets. The GARP ${ }^{+}$LAP $^{-}$and GARP ${ }^{-}$LAP $^{-}$T cell subsets produced negligible amounts of IL-10 in both HD and LICRC samples.

Interestingly, levels of IL-10-secreting $\mathrm{CD}^{+} \mathrm{T}$ cells within $\mathrm{GARP}^{+} \mathrm{LAP}^{+}$and $\mathrm{GARP}^{-} \mathrm{LAP}^{+}$subsets were significantly higher in LICRC patients than HD (Figure 7C). The increase in IL-10 secretion in LICRC patients was further confirmed by measuring IL-10 secretion in the whole $\mathrm{CD}^{+} \mathrm{T}$ cell population (Figure $8 \mathrm{~A}$ and $8 \mathrm{~B}$ ), thus confirming the immunosuppressive milieu in cancer patients. When LICRC patients were stratified according to TNM staging, $\mathrm{CD}^{+}{ }^{+} \mathrm{T}$ cells from LICRC patients with stage III made significantly higher levels of IL-10 than patients with stage I and II (Figure 8C and $8 \mathrm{D})$. Of interest, there was no significant increase in IFN- $\gamma$-secreting $\mathrm{CD}^{+} \mathrm{T}$ cells between HD and LICRC patients or between LICRC patients with different staging (Figure 8).

\section{DISCUSSION}

In this study, we found that FoxP $3^{+/}$Helios $^{+}$Tregs were significantly expanded in the peripheral blood of LICRC patients, compared with healthy donors and PC patients in non-activated and activated settings. Further defining Tregs by expression of GARP and LAP showed that FoxP3- ${ }^{-} \mathrm{AP}^{+}$Tregs and activated FoxP3 ${ }^{+/}$ Helios $^{+} \mathrm{GARP}^{+} \mathrm{LAP}^{+}$Tregs were significantly expanded in
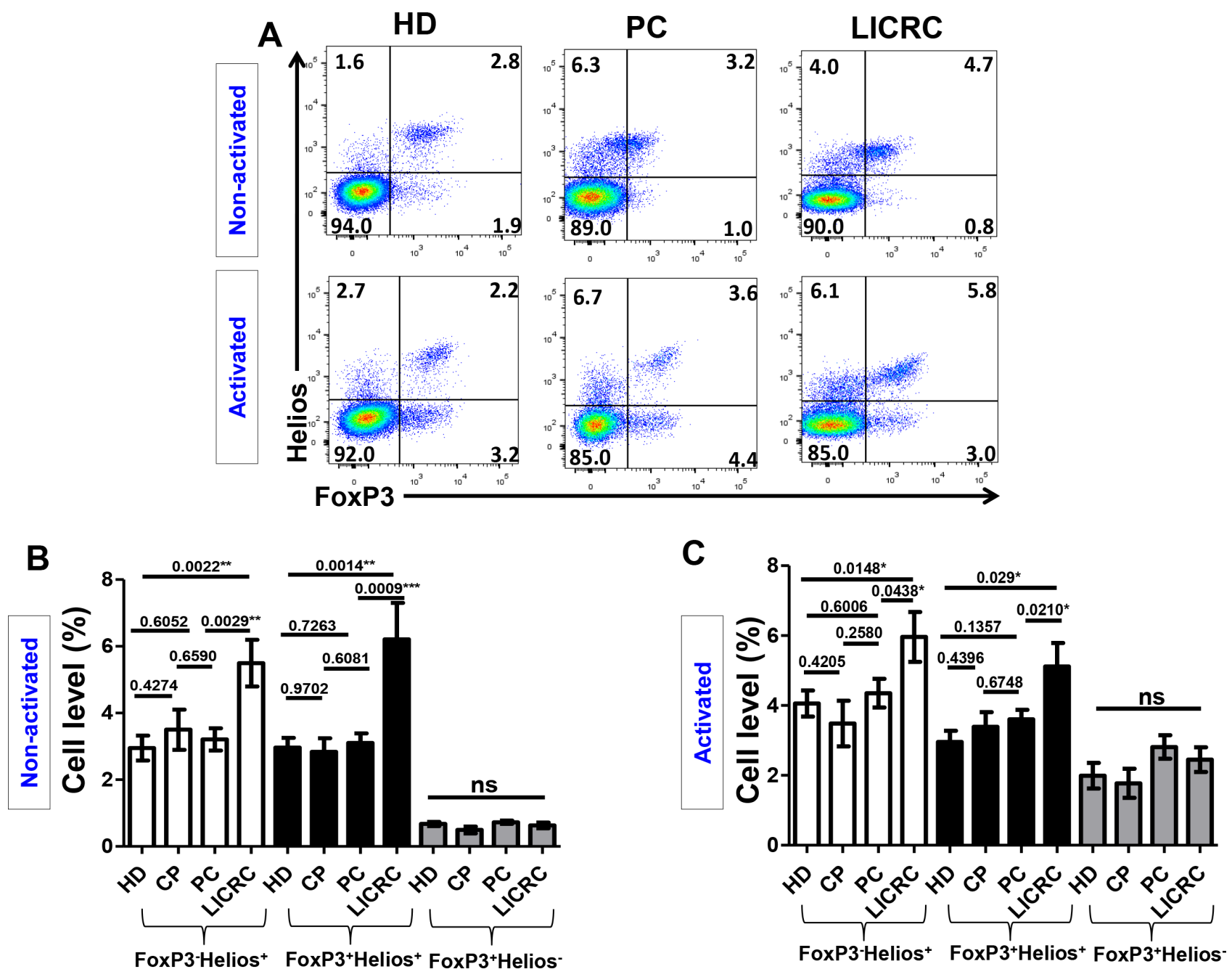

Figure 4: Expression of FoxP3 and Helios on non-activated and activated CD3 $^{+}$CD4 ${ }^{+}$T cells. (A) Representative flow cytometric plots showing the expression of FoxP3 against Helios on healthy donors and cancer patients. (B) Bar charts show the mean percentages \pm SEM of FoxP3-Helios ${ }^{+}$, FoxP $3^{+}$Helios $^{+}$and FoxP ${ }^{+}{ }^{+}$Helios ${ }^{-} \mathrm{T}$ cell subsets in non-activated PBMCs isolated from 14 healthy donors (HD), 7 chronic pancreatitis (CP), 17 pancreatic cancer (PC) and 7 liver metastases from colorectal cancer (LICRC) patients. (C) Bar charts show the mean percentages \pm SEM of FoxP3 ${ }^{-} \mathrm{Helios}^{+}$, FoxP3 ${ }^{+} \mathrm{Helios}^{+}$and $\mathrm{FoxP}^{+}{ }^{+} \mathrm{Helios}^{-} \mathrm{T}$ cell subsets in activated $\mathrm{PBMCs}$ isolated from $18 \mathrm{HD}, 9 \mathrm{CP}, 20 \mathrm{PC}$ and 11 LICRC patients. 

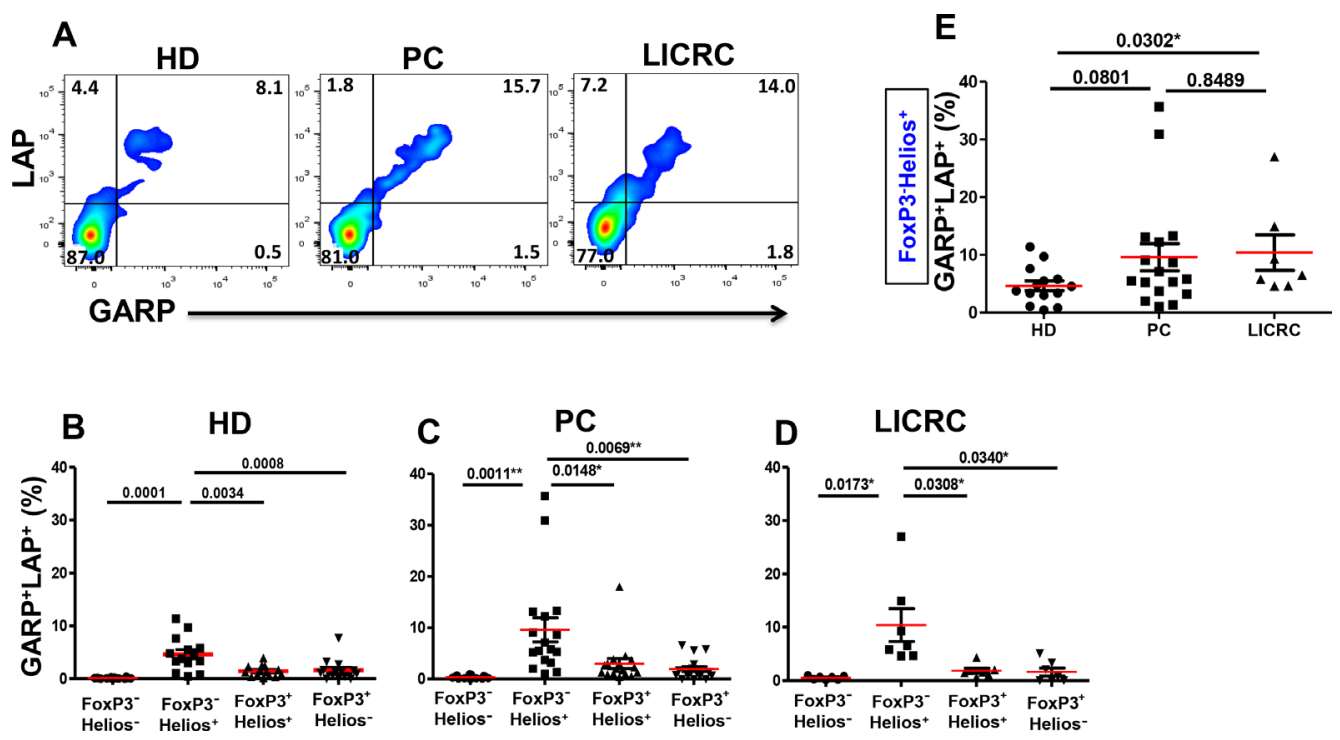

Figure 5: Expression of GARP and LAP on non-activated FoxP3 ${ }^{+/}$Helios $^{+/}$T-cell subsets. (A) Representative flow cytometric plots showing LAP/GARP expression on FoxP3-Helios ${ }^{+}$T-cell subset in non-activated PBMCs from healthy donors (HD) and patients with pancreatic cancer (PC) or liver metastases from colorectal cancer (LICRC). (B) Scatter plots showing the mean percentages \pm SEM of GARP ${ }^{+} \mathrm{LAP}^{+}$cells within FoxP3 ${ }^{+/}$Helios $^{+-}$T-cell subsets in non-activated PBMCs isolated from 14 HD (B), 17 PC (C) and 7 LICRC patients (D). (E) Scatter plots comparing the mean percentages \pm SEM of GARP ${ }^{+}$APP $^{+}$cells within non-activated FoxP3 ${ }^{-}$Helios $^{+} \mathrm{T}^{-}$-cell $^{-}$ subset in HD, PC and LICRC patients.
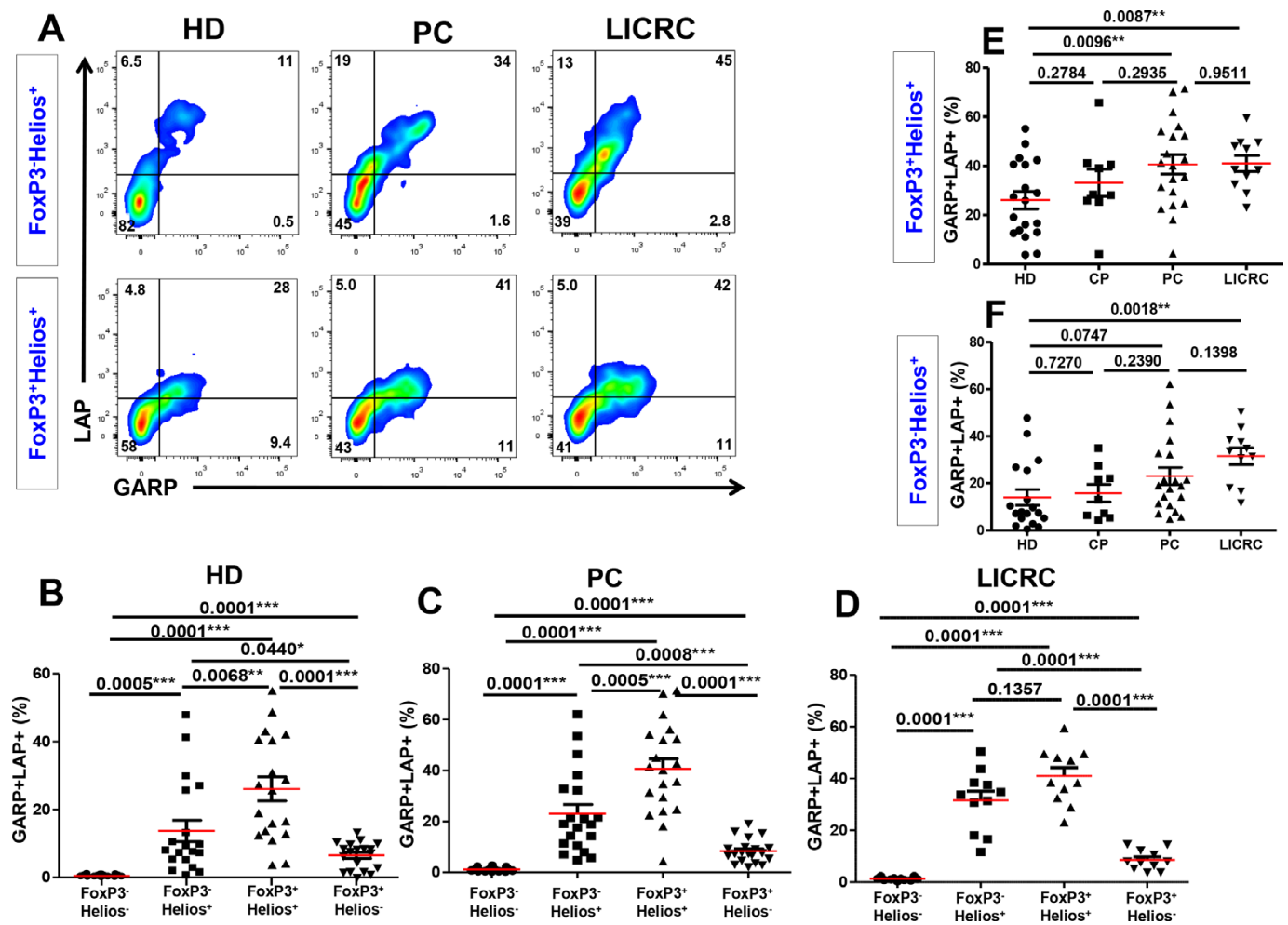

Figure 6: Expression of GARP and LAP on different FoxP3 $^{+/} \mathrm{Helios}^{+/}$T-cell subsets in the activated setting. (A) Representative flow cytometric plots showing LAP/GARP expression on FoxP3-Helios ${ }^{+}$and FoxP3 ${ }^{+} \mathrm{Helios}^{+} \mathrm{T}^{-}$-eell subsets in activated PBMCs from healthy donors (HD), pancreatic cancer (PC) and liver metastases from colorectal cancer (LICRC) patients. (B) Scatter plots show the mean percentages \pm SEM of $\mathrm{GARP}^{+} \mathrm{LAP}^{+}$cells within $\mathrm{FoxP}^{+/-} \mathrm{Helios}^{+/-}$T-cell subsets in activated PBMCs isolated from $18 \mathrm{HD}$ (B), $20 \mathrm{PC}(\mathbf{C})$ and 11 LICRC patients (D). Scatter plots comparing the mean percentages $\pm \mathrm{SEM}$ of GARP $\mathrm{LAP}^{+}$cells within activated FoxP3 $^{+} \mathrm{Helios}^{+}(\mathbf{E})$ and FoxP3-Helios ${ }^{+}(\mathbf{F})$ T-cell subset in HD, CP, PC and LICRC patients. 
cancer patients.

FoxP3- ${ }^{-} \mathrm{AP}^{+}$Tregs were identified as a novel suppressive Treg subset in healthy donors where they made up approximately $2 \%$ of the circulating $\mathrm{CD}^{+} \mathrm{T}$ cell compartment [28]. Several groups have since characterized highly suppressive FoxP $3^{+/} \mathrm{LAP}^{+}$Tregs in healthy donors and cancer patients [24, 29-31]. The nature of GARP and LAP expression on T cells in cancer remains uncertain. In patients with head and neck squamous cell carcinoma, highly suppressive $\mathrm{CD}^{+} \mathrm{CD} 39^{+} \mathrm{GARP}^{+} \mathrm{LAP}^{+}$Tregs were expanded following chemoradiation therapy [32]. In hepatocellular carcinoma and ovarian cancer, GARPexpressing FoxP $3^{+}$Tregs were expanded in the peripheral blood and ascites, respectively $[6,33]$. In colorectal cancer patients, FoxP3 ${ }^{-} \mathrm{LAP}^{+}$Tregs have been correlated with cancer progression and were reported to be expanded in the peripheral blood of patients with tumor metastases, compared with healthy donors and non-metastatic patients [29-31]. Another study reported that FoxP3-LAP ${ }^{+}$TI Tregs isolated from tumour tissue exhibited potent in vitro suppressive activity mediated by TGF- $\beta$ and IL-10, and were up to 50-fold more suppressive than 'conventional' FoxP $^{+}$Tregs [31]. In this study, we confirmed the presence of a significant peripheral blood FoxP3 ${ }^{-} \mathrm{LAP}^{+}$ Treg subset, and the majority of these cells co-expressed GARP and Helios.

We found that FoxP3-Helios ${ }^{+} \mathrm{GARP}^{+} \mathrm{LAP}^{+}$Tregs were significantly expanded in LICRC patients, while FoxP ${ }^{+} \mathrm{Helios}^{+} \mathrm{GARP}^{+} \mathrm{LAP}^{+}$Tregs were significantly increased in PC and LICRC patients. The selective
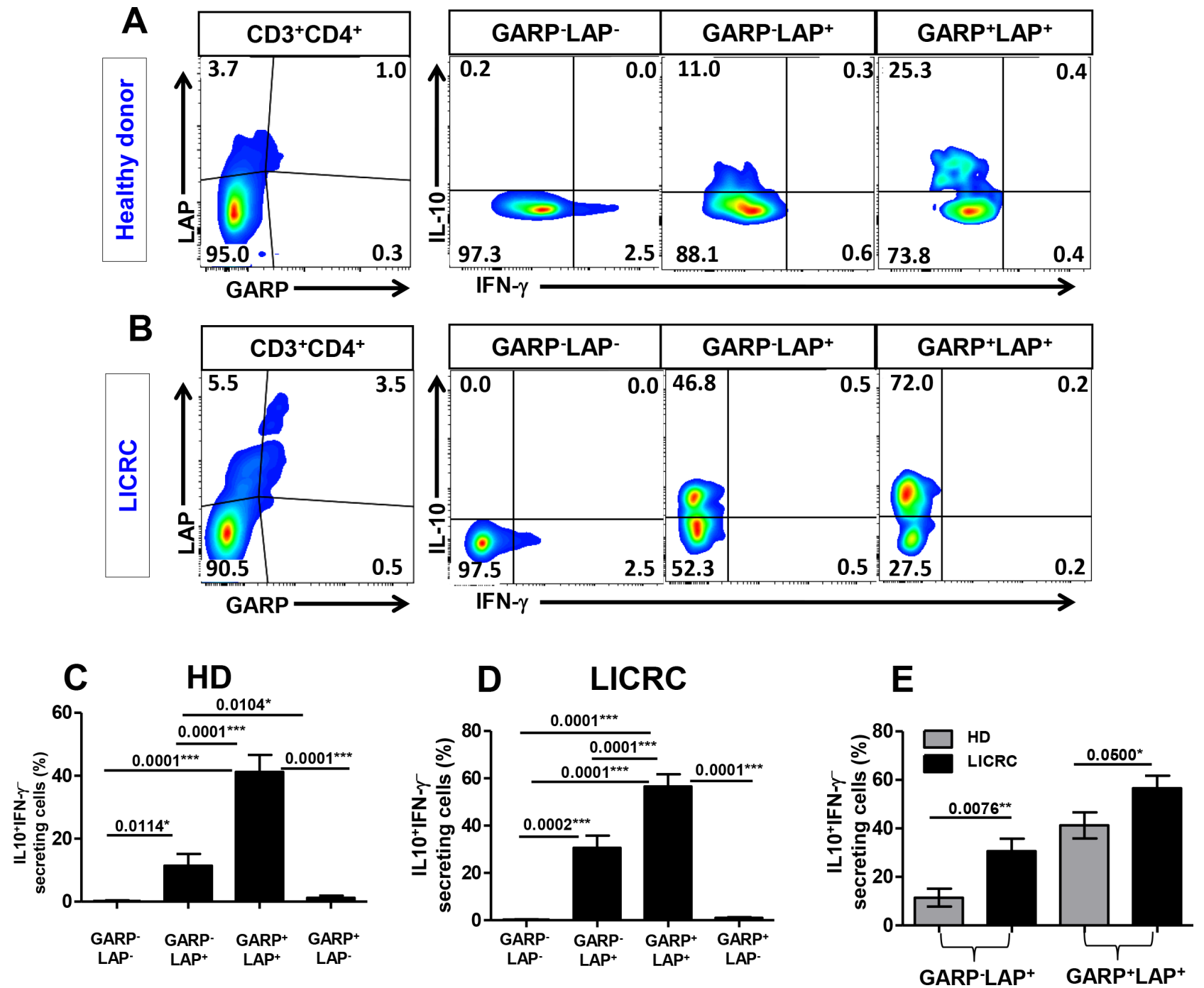

Figure 7: Intracellular cytokine secretion from different $\mathbf{G A R P}^{+/} \mathbf{L A P} \mathbf{P}^{+/-} \mathbf{C D 4} \mathbf{4}^{+} \mathbf{T}$ cell subsets. Representative flow cytometric plots showing GARP/LAP expression on activated CD $3{ }^{+} \mathrm{CD} 4^{+} \mathrm{T}$ cells and levels of IFN- $\gamma$ and IL- 10 secretion from different $\mathrm{GARP}^{+/-} \mathrm{LAP}^{+/-} \mathrm{CD}^{+} \mathrm{T}$ cell subsets isolated from peripheral blood of a healthy donor $(\mathbf{A})$ and LICRC patient $(\mathbf{B})$. Bar charts show the mean percentage \pm SEM of IL-10 $10^{+} \mathrm{IFN}-\gamma^{-}$cells within $\mathrm{GARP}^{+/-} \mathrm{LAP}^{+-} \mathrm{CD} 4^{+} \mathrm{T}$ cell subsets in PBMCs isolated from 10 healthy donors $(\mathbf{C})$ and 10 LICRC patients (D). Bar chart comparing the mean percentage \pm SEM of IL-10 ${ }^{+}$IFN- $\gamma^{-}$cells within GARP- $^{-} \mathrm{LPP}^{+}$and $\mathrm{GARP}^{+} \mathrm{LAP}^{+} \mathrm{CD}^{+}$ T-cell subsets between HD and LICRC patients (E). 
co-expression of GARP/LAP with Helios is intriguing. Helios $^{+}$Tregs have been shown to overexpress TGF- $\beta$ and to exhibit potent TGF- $\beta$ mediated suppressive activity [21]. While we did not test the suppressive function of Helios $^{+/-}$T cell subsets, GARP/LAP co-expression could indicate a robust TGF- $\beta$ mediated suppressive mechanism. There have been limited investigations into GARP/LAP expression with FoxP3 and Helios. GARP and FoxP3 have been proposed to form a positive feedback loop, although more recent work showed that regulation of GARP is independent of FoxP3 and GARP was also shown not to correlate with Helios expression in FoxP $3^{+} \mathrm{T}$ cells $[34,35]$. It remains to be confirmed if there is any mechanistic link between GARP/LAP expression and Helios expression.

The increased levels of FoxP ${ }^{+/}{ }^{-}$Helios $^{+} \mathrm{GARP}^{+} \mathrm{LAP}^{+}$ Tregs in LICRC patients could be attributed to the advanced metastatic stage of these patients, and the associated tumourmediated immunosuppression that could be expected. In the activated setting, FoxP $3^{+} \mathrm{Helios}^{+} \mathrm{GARP}^{+} \mathrm{LAP}^{+}$ Tregs outnumbered FoxP3 ${ }^{-}$Helios $^{+} \mathrm{GARP}^{+} \mathrm{LAP}^{+}$Tregs in all samples. The underlying reasons for this are not immediately clear. However, FoxP $3^{+} \mathrm{Helios}^{+}$Tregs have been shown to preferentially expand in vivo compared to FoxP $3^{+}$Helios $^{-}[27,36]$.
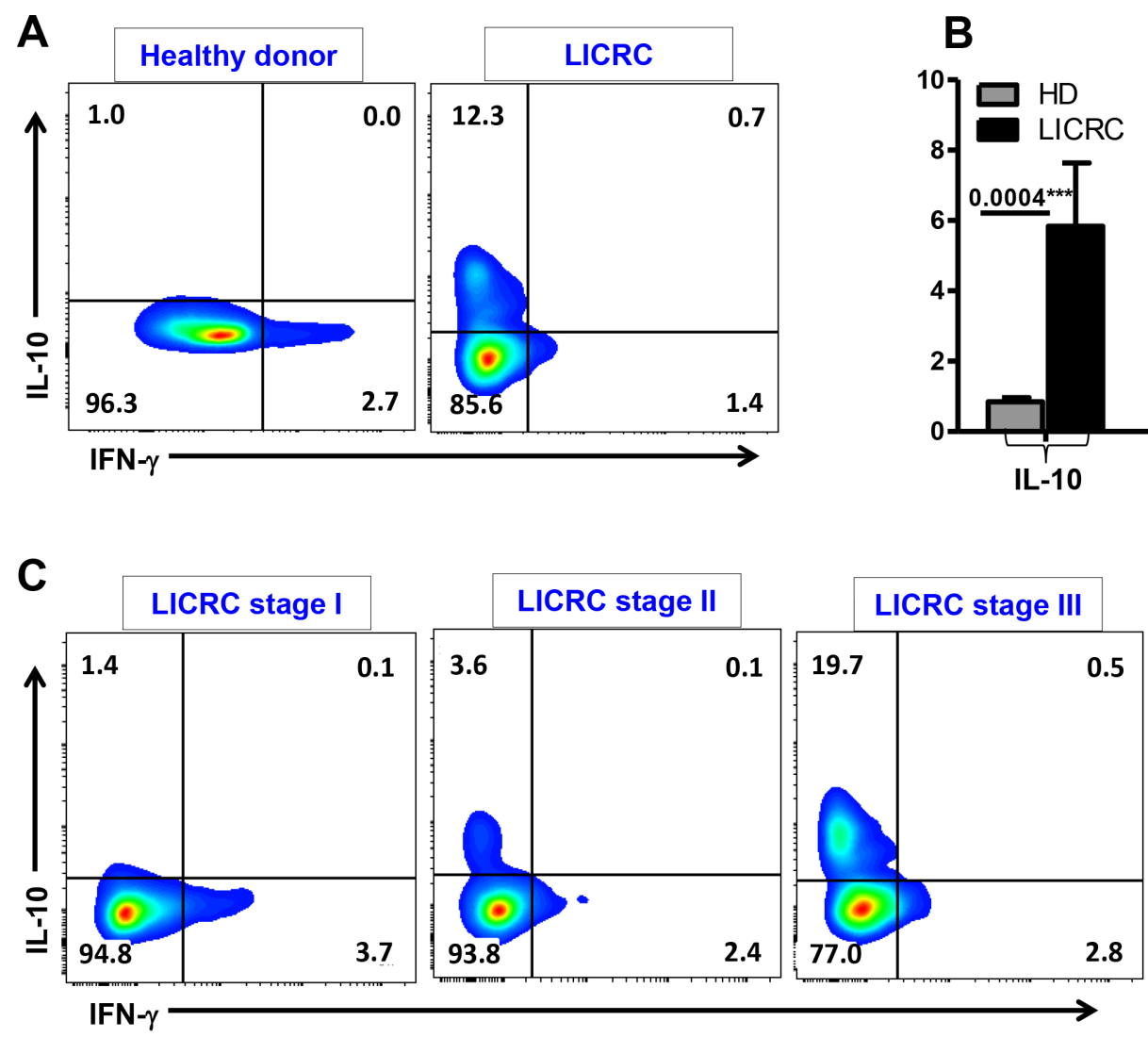

IFN- $\gamma$
Interestingly, GARP and LAP were expressed at relatively high levels on the FoxP3 ${ }^{-} \mathrm{Helios}^{+}$Treg subset in the non-activated setting, and they were expanded in LICRC patients (HD: 5\%, LICRC: $\sim 10 \%$ ). This FoxP3Helios $^{+} \mathrm{GARP}^{+} \mathrm{LAP}^{+}$Treg subset has not been previously described and could represent the novel FoxP $3^{-} \mathrm{LAP}^{+}$Treg subset described in previous studies [28, 31], emphasizing the importance of Helios as a Treg marker. However, the suppressive ability of this Treg subset will need to be confirmed in functional studies.

We also found that cells from LICRC patients secrete more IL-10, which is confined to the $\mathrm{GARP}^{+/} \mathrm{LAP}^{+}$ T-cell compartments. Interestingly, LICRC patients with higher TNM staging had higher levels of IL-10-secreting $\mathrm{CD}^{+} \mathrm{T}$ cells. This increase in IL-10 might be indicative of increased Treg activity, especially given the advanced metastatic stage of LICRC patients. Our findings support the role of GARP/LAP as markers of IL-10-secreting Tregs, while co-expression of GARP/LAP also infer the potential of a TGF- $\beta$ mediated suppressive mechanism of these cells.

Our data support the role of GARP and LAP as markers of Tregs, and potentially novel immunotherapy targets. GARP-blocking antibodies have already

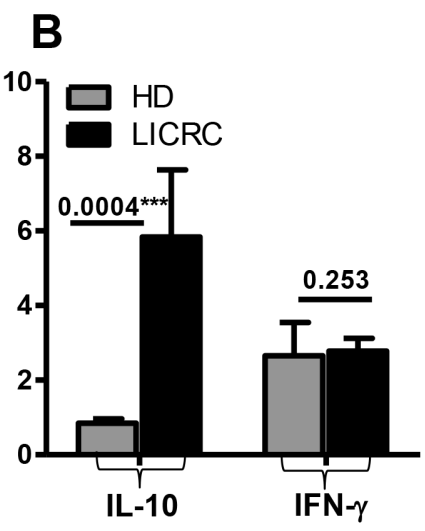

Figure 8: Intracellular cytokine secretion from $\mathbf{C D 4}^{+} \mathbf{T}$ cells. Representative flow cytometric plots showing IFN- $\gamma$ and IL-10 secretion from activated $\mathrm{CD}^{+} \mathrm{CD}^{+} \mathrm{T}$ cells isolated from peripheral blood of a healthy donor and LICRC patient (A), and LICRC patients with TNM staging I, II and III (C). Bar chart shows the mean percentage \pm SEM of IL-10- and IFN- $\gamma$-secreting CD4 ${ }^{+} \mathrm{T}_{\text {cells in PBMCs }}$ isolated from 9 healthy donors and 10 LICRC patients (B), and 5 LICRC patients with staging I/II and 5 patients with staging III (D). 
been developed and shown to inhibit Treg activity in a xenogeneic model of graft-versus-host-disease [37]. In the absence of further clinical and functional data, we cannot comment on the exact nature and origin of $\mathrm{FoxP}^{+/-} \mathrm{Helios}^{+} \mathrm{GARP}^{+} \mathrm{LAP}^{+}$Tregs whether thymic or peripheral or even induced in the tumour microenvironment. Investigating the correlation between the levels of these Treg subsets and disease prognosis was not possible due to the relatively small number of samples, and it is imperative to investigate this correlation. Further studies are required to confirm the nature, origin and clinical impact of the FoxP $^{+/-}$Helios $^{+} \mathrm{GARP}^{+} \mathrm{LAP}^{+} \mathrm{T}$ cell subsets identified in this study. It will also be important to elucidate the role of Helios expression in Tregs and T cells, whether as an activation marker or as part of a suppressive mechanism.

Taken together, our results indicate that studies investigating Tregs in different pathological settings should consider different Treg-related markers such as GARP, LAP, Helios, and not only FoxP3 as a sole Tregspecific marker. Understanding the role and contribution of specific Treg subsets in various pathological settings will enable the development of effective immunotherapies, targeting only the most 'pathological' or suppressive Treg subsets as opposed to systemic therapies.

\section{MATERIALS AND METHODS}

\section{Collection of blood samples}

The research protocol was approved by the UK National Research Ethical Committee, Salford Research Ethics Committee and the Local Research and Development Departments. Written consent was obtained from all patients and healthy donors before blood collection. Samples were collected from patients with chronic pancreatitis ( $\mathrm{CP}, n=9)$, malignant pancreatic cancer (PC, $n=20$ ) or liver metastases from colorectal cancer (LICRC, $n=11$ ) at the North Manchester General Hospital, UK. Table 1 shows the characteristic features of all patients in this study. In addition, blood samples were collected from healthy donors (HD) as controls. Blood samples were collected in a $50 \mathrm{ml}$ Falcon tube containing $200 \mu \mathrm{l}(1000 \mathrm{IU} / \mathrm{ml})$ heparin.

\section{Cell isolation and preparation}

Peripheral blood mononuclear cells (PBMCs) were isolated from whole blood using Ficoll-Hypaque (SigmaAldrich, UK) density gradient centrifugation. PBMCs were then frozen at $5-10 \times 10^{6}$ cells $/ \mathrm{ml}$ in cryovials in $1 \mathrm{ml}$ of freezing media (50\% FCS, 40\% RPMI-1640 and $10 \%$ DMSO) and stored in liquid nitrogen (LN) for later use. Trypan blue was used for PBMC viability testing and counting.

\section{In vitro $\mathbf{T}$ cell culture}

PBMCs were thawed and suspended at $2 \times 10^{6}$ cells/ well in $2 \mathrm{ml}$ complete medium [RPMI-1640 supplemented with L-glutamine $2 \mathrm{mM}, 10 \%$ FCS, Streptomycin $100 \mu \mathrm{g} /$ $\mathrm{ml}$ and Penicillin 100 Units/ml]. 24-well non-treated culture plates were pre-coated with plate-bound $2 \mu \mathrm{g} / \mathrm{ml}$ anti-CD3 antibody (OKT3 clone, eBioscience, Hatfield, $\mathrm{UK}$ ) and $2 \mu \mathrm{g} / \mathrm{ml}$ anti-CD28 antibody (CD28.2 clone, eBioscience) for 2.5 hours at $37^{\circ} \mathrm{C}$. PBMCs were either plated as 'non-activated' in non-coated wells or 'activated' in pre-coated wells. Plated cells were incubated for 18-20 hours in a humidified incubator at $37^{\circ} \mathrm{C}$ and $5 \%$ $\mathrm{CO}_{2}$. Cells were collected and blocked for FcR with $\mathrm{IgG}$ from human serum (Sigma-Aldrich), ready for staining and flow cytometric analysis.

\section{Cell staining and flow cytometric analysis}

Surface staining: Cells were then washed and labeled for surface markers: mouse anti-human CD4PerCP-Cy5.5 (RPA-T4 clone, eBioscience), mouse antihuman CD3-APC-H7 (SK7 clone, BD Biosciences, Oxford, UK), mouse anti-human GARP-APC (7B11 clone, BD Biosciences), and mouse anti-human LAP-PE (TW4-2F8 clone, BD Biosciences). Intracellular staining: Fixation, permeabilization and flow cytometry buffers were from eBioscience or BD Biosciences and prepared as per the manufacturer's instructions. Following staining for surface markers, cells were fixed and permeabilized at $4^{\circ} \mathrm{C}$ for 45 minutes using fixation/permeabilization buffer. Cells were then blocked for 15 minutes using rat serum (eBioscience) and mouse serum (Sigma-Aldrich) before staining with rat anti-human FoxP3-PE-Cy7 (PCH101 clone, eBioscience) and Armenian hamster anti-mouse/ human Helios-FITC (22F6 clone, Biolegend, Cambridge, UK) for 30 minutes at $4^{\circ} \mathrm{C}$. Following two further permeabilization washes using permeablization buffer, cells were resuspended in flow cytometry buffer. Cytokine detection: Thawed PBMCs were plated in complete medium in a 24-well non-treated culture plate pre-coated with $2 \mu \mathrm{g} / \mathrm{ml}$ anti-CD3 and $2 \mu \mathrm{g} / \mathrm{ml}$ anti-CD28. To investigate IFN- $\gamma$ and IL-10 release from $\mathrm{GARP}^{+/} \mathrm{LAP}^{+/-}$ Treg subpopulations, cells were incubated for 24 hours at $37^{\circ} \mathrm{C}$ and $5 \% \mathrm{CO}_{2} .1 \mu \mathrm{g} / \mathrm{ml}$ Golgi Plug (BD Biosciences) was added for the last 4 hours of activation. Cells were first stained for surface markers using mouse anti-human CD4PerCP-Cy5.5, mouse anti-human CD3-APC-H7, mouse anti-human GARP-APC, and mouse anti-human LAP-PE. For intracellular cytokines, cells were subsequently fixed, permeabilized and blocked using mouse serum before staining with mouse anti-human IL-10-FITC (BT-10 clone, eBioscience) and mouse anti-human IFN- $\gamma$-PE-Cy7 (4S.B3 clone, BD Pharmingen, BD Biosciences, UK).

Flow cytometric data was acquired on FACSVerse or FACSCanto II flow cytometers (BD Biosciences, USA). 
Data analysis was performed using BD FACSuite or FlowJo 10.0.8r1 software.

\section{Statistical analysis}

Statistical analysis was performed using GraphPad Prism 5.0 software (GraphPad Software, USA). Paired $T$ test or unpaired/Mann-Whitney tests were used to examine for differences within groups or between groups, respectively. $P$ value $\leq 0.05$ was considered statistically significant. The data are presented as means \pm SEM.

\section{ACKNOWLEDGMENTS AND FUNDING}

We are grateful for patients and donors for their donation of blood samples. This work was supported by grants from North Manchester Health Care Trust (grant no ELRA60), Salford Royal NHS Foundation Trust (grant no ELRA58), National Research Foundation, UAE University (grant no 31M093) and the Terry Fox Foundation (grant no 21M094).

\section{CONFLICTS OF INTEREST}

All authors declare no conflicts of interest.

\section{REFERENCES}

1. Sakaguchi S, Yamaguchi T, Nomura T, Ono M. Regulatory T cells and immune tolerance. Cell. 2008; 133:775-787.

2. Elkord E, Alcantar-Orozco EM, Dovedi SJ, Tran DQ, Hawkins RE, Gilham DE. T regulatory cells in cancer: recent advances and therapeutic potential. Expert Opin Biol Ther. 2010; 10:1573-1586.

3. Nishikawa H, Sakaguchi S. Regulatory T cells in cancer immunotherapy. Curr Opin Immunol. 2014; 27:1-7.

4. Chaudhary B, Abd Al Samid M, al-Ramadi BK, Elkord E. Phenotypic alterations, clinical impact and therapeutic potential of regulatory $\mathrm{T}$ cells in cancer. Expert Opin Biol Ther. 2014; 14:931-945.

5. Hiraoka N, Onozato K, Kosuge T, Hirohashi S. Prevalence of FOXP3+ regulatory $\mathrm{T}$ cells increases during the progression of pancreatic ductal adenocarcinoma and its premalignant lesions. Clin Cancer Res. 2006; 12: 5423-5434.

6. Kalathil S, Lugade AA, Miller A, Iyer R, Thanavala Y. Higher frequencies of GARP $(+)$ CTLA-4(+)Foxp3(+) T regulatory cells and myeloid-derived suppressor cells in hepatocellular carcinoma patients are associated with impaired T-cell functionality. Cancer Res. 2013; 73:2435-2444.

7. Pedroza-Gonzalez A, Verhoef C, Ijzermans JN, Peppelenbosch MP, Kwekkeboom J, Verheij J, Janssen HL, Sprengers D. Activated tumor-infiltrating CD4+ regulatory $\mathrm{T}$ cells restrain antitumor immunity in patients with primary or metastatic liver cancer. Hepatology. 2013; 57:183-194.
8. Mattarollo SR, Steegh K, Li M, Duret H, Foong Ngiow S, Smyth MJ. Transient Foxp3(+) regulatory T-cell depletion enhances therapeutic anticancer vaccination targeting the immune-stimulatory properties of NKT cells. Immunol Cell Biol. 2013; 91:105-114.

9. Singer BD, King LS, D'Alessio FR. Regulatory T cells as immunotherapy. Front Immunol. 2014; 5:46.

10. Wolf D, Wolf AM. CCR 20th Anniversary Commentary: From Regulatory $\mathrm{T}$ Cells to Checkpoint Monoclonal Antibodies-Immuno-oncology Advances Clinical Cancer Research. Clin Cancer Res. 2015; 21:2657-2659.

11. Dong S, Maiella S, Xhaard A, Pang Y, Wenandy L, Larghero J, Becavin C, Benecke A, Bianchi E, Socie G, Rogge L. Multiparameter single-cell profiling of human CD4+FOXP3+ regulatory T-cell populations in homeostatic conditions and during graft-versus-host disease. Blood. 2013; 122:1802-1812.

12. Duhen T, Duhen R, Lanzavecchia A, Sallusto F, Campbell DJ. Functionally distinct subsets of human FOXP3+ Treg cells that phenotypically mirror effector Th cells. Blood. 2012; 119:4430-4440

13. Gratz IK, Campbell DJ. Organ-specific and memory treg cells: specificity, development, function, and maintenance. Front Immunol. 2014; 5:333.

14. Liston A, Gray DH. Homeostatic control of regulatory $\mathrm{T}$ cell diversity. Nat Rev Immunol. 2014; 14:154-165.

15. Mason GM, Lowe K, Melchiotti R, Ellis R, de Rinaldis E, Peakman M, Heck S, Lombardi G, Tree TI. Phenotypic Complexity of the Human Regulatory T Cell Compartment Revealed by Mass Cytometry. J Immunol. 2015; 195: 2030-2037.

16. Santegoets SJ, Dijkgraaf EM, Battaglia A, Beckhove P, Britten CM, Gallimore A, Godkin A, Gouttefangeas C, de Gruijl TD, Koenen HJ, Scheffold A, Shevach EM, Staats J, et al. Monitoring regulatory $\mathrm{T}$ cells in clinical samples: consensus on an essential marker set and gating strategy for regulatory $\mathrm{T}$ cell analysis by flow cytometry. Cancer Immunol Immunother. 2015; 64:1271-1286.

17. Liston A, Piccirillo CA. Developmental plasticity of murine and human Foxp3(+) regulatory T cells. Adv Immunol. 2013; 119:85-106.

18. Sebastian M, Lopez-Ocasio M, Metidji A, Rieder SA, Shevach EM, Thornton AM. Helios Controls a Limited Subset of Regulatory T Cell Functions. J Immunol. 2016; 196:144-155.

19. Takatori H, Kawashima H, Matsuki A, Meguro K, Tanaka S, Iwamoto T, Sanayama Y, Nishikawa N, Tamachi T, Ikeda K, Suto A, Suzuki K, Kagami S, et al. Helios Enhances Treg Cell Function in Cooperation With FoxP3. Arthritis Rheumatol. 2015; 67:1491-1502.

20. Elkord E, Al-Ramadi BK. Helios expression in FoxP3(+) T regulatory cells. Expert Opin Biol Ther. 2012; 12:1423-1425.

21. Zabransky DJ, Nirschl CJ, Durham NM, Park BV, Ceccato CM, Bruno TC, Tam AJ, Getnet D, Drake CG. 
Phenotypic and functional properties of Helios + regulatory T cells. PLoS One. 2012; 7:e34547.

22. Rifkin DB. Latent transforming growth factor-beta (TGF-beta) binding proteins: orchestrators of TGF-beta availability. J Biol Chem. 2005; 280:7409-7412.

23. Tran DQ, Andersson J, Wang R, Ramsey H, Unutmaz D, Shevach EM. GARP (LRRC32) is essential for the surface expression of latent TGF-beta on platelets and activated FOXP3+ regulatory T cells. Proc Natl Acad Sci U S A. 2009; 106:13445-13450.

24. Sun J, Tang DN, Fu T, Sharma P. Identification of human regulatory $\mathrm{T}$ cells in the setting of T-cell activation and anti-CTLA-4 immunotherapy on the basis of expression of latency-associated peptide. Cancer Discov. 2012; 2: 122-130.

25. Tran DQ, Andersson J, Hardwick D, Bebris L, Illei GG, Shevach EM. Selective expression of latency-associated peptide (LAP) and IL-1 receptor type I/II (CD121a/ CD121b) on activated human FOXP3+ regulatory T cells allows for their purification from expansion cultures. Blood. 2009; 113:5125-5133.

26. Elkord E, Abd Al Samid M, Chaudhary B. Helios, and not FoxP3, is the marker of activated Tregs expressing GARP/ LAP. Oncotarget. 2015; 6:20026-20036. doi: 10.18632/ oncotarget. 4771 .

27. Elkord E, Sharma S, Burt DJ, Hawkins RE. Expanded subpopulation of FoxP3 $+\mathrm{T}$ regulatory cells in renal cell carcinoma co-express Helios, indicating they could be derived from natural but not induced Tregs. Clin Immunol. 2011; 140:218-222.

28. Gandhi R, Farez MF, Wang Y, Kozoriz D, Quintana FJ, Weiner HL. Cutting edge: human latency-associated peptide $+\mathrm{T}$ cells: a novel regulatory $\mathrm{T}$ cell subset. J Immunol. 2010; 184:4620-4624.

29. Mahalingam J, Lin YC, Chiang JM, Su PJ, Fang JH, Chu YY, Huang CT, Chiu CT, Lin CY. LAP $+\mathrm{CD} 4+\mathrm{T}$ cells are suppressors accumulated in the tumor sites and associated with the progression of colorectal cancer. Clin Cancer Res. 2012; 18:5224-5233.

30. Mahalingam J, Lin CY, Chiang JM, Su PJ, Chu YY, Lai HY, Fang JH, Huang CT, Lin YC. CD4(+) T cells expressing latency-associated peptide and Foxp3 are an activated subgroup of regulatory $\mathrm{T}$ cells enriched in patients with colorectal cancer. PLoS One. 2014; 9:e108554.
31. Scurr M, Ladell K, Besneux M, Christian A, Hockey T, Smart K, Bridgeman H, Hargest R, Phillips S, Davies M, Price D, Gallimore A, Godkin A. Highly prevalent colorectal cancer-infiltrating $\mathrm{LAP}(+)$ Foxp3(-) T cells exhibit more potent immunosuppressive activity than Foxp3(+) regulatory T cells. Mucosal Immunol. 2014; 7:428-439.

32. Schuler PJ, Harasymczuk M, Schilling B, Saze Z, Strauss L, Lang S, Johnson JT, Whiteside TL. Effects of adjuvant chemoradiotherapy on the frequency and function of regulatory $\mathrm{T}$ cells in patients with head and neck cancer. Clin Cancer Res. 2013; 19:6585-6596.

33. Govindaraj C, Scalzo-Inguanti K, Madondo M, Hallo J, Flanagan K, Quinn M, Plebanski M. Impaired Th1 immunity in ovarian cancer patients is mediated by TNFR2+ Tregs within the tumor microenvironment. Clin Immunol. 2013; 149:97-110.

34. Akimova T, Beier UH, Wang L, Levine MH, Hancock WW. Helios expression is a marker of $\mathrm{T}$ cell activation and proliferation. PLoS One. 2011; 6:e24226.

35. Probst-Kepper M, Buer J. FOXP3 and GARP (LRRC32): the master and its minion. Biol Direct. 2010; 5:8.

36. Alexander T, Sattler A, Templin L, Kohler S, Gross C, Meisel A, Sawitzki B, Burmester GR, Arnold R, Radbruch A, Thiel A, Hiepe F. Foxp3+ Helios+ regulatory T cells are expanded in active systemic lupus erythematosus. Ann Rheum Dis. 2013; 72:1549-1558.

37. Cuende J, Lienart S, Dedobbeleer O, van der Woning B, De Boeck G, Stockis J, Huygens C, Colau D, Somja J, Delvenne P, Hannon M, Baron F, Dumoutier L, et al. Monoclonal antibodies against GARP/TGF-beta1 complexes inhibit the immunosuppressive activity of human regulatory T cells in vivo. Sci Transl Med. 2015; 7:284ra256. 